\title{
Spiritual struggles and health: Assessing the influence of socioeconomic status
}

Neal Krause*

University of Michigan

Kenneth I. Pargament

Bowling Green State University

Gail Ironson

University of Miam

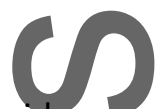

Abstract

Growing evidence suggests that spiritual struggles may play a major role in explaining the relationship between religion and health. Even so, there are significant gaps in the literature. More specifically, researchers do not know enough about how spiritual struggles arise in the first place.

The current study has two major goals. The first is to see whether socioeconomic status is associated with spiritual struggles. The second is to see whether spiritual struggles are associated with physical health. A conceptual model is tested that contains the following core hypotheses: (1) individuals with lower levels of educational attainment are more likely to encounter chronic economic difficulties; (2) people who experience ongoing financial strain are more likely to live in rundown neighborhoods; (3) people who live in dilapidated neighborhoods will be more angry than their wellto-do counterparts, (4) people who are more angry will, in turn, be more likely to experience spiritual struggles; and (5) greater spiritual struggles will be associated with more symptoms of physicalillness. Data from a recent nationwide survey $(N=2,146)$ provide empirical support for each hypothesis,

Keywords: socioeconomic; spiritual struggles; health

Note: This research was supported by a grant from the John Tempelton Foundation.

This is the author manuscript accepted for publication and has undergone full peer review but has not been through the copyediting, typesetting, pagination and proofreading process, which may lead to differences between this version and the Version of Record. Please cite this article as doi: $\underline{10.1111 / \text { jssr. } 12364 .}$.

This article is protected by copyright. All rights reserved. 
Correspondence: Neal Krause, Department of Health Behavior and Health Education, School of Public Health, University of Michigan, 1420 Washington Heights, Ann Arbor, MI 48109-2029. Phone: (734) 763-5583; fax: (734) 763-7379; e-mail: nkrause@umich.edu.

\section{Introduction}

Spiritual struggles have rapidly become one of the major constructs in the quest to explain the relationship between religion and health (Pargament, Murray-Swank, Magyar and Ano 2005). Spiritual struggles refer to difficulties that a person may encounter with their faith and include having a troubled relationship with God (e.g., feeling abandoned by God, feeling punished by God), encountering difficulties with others (e.g., feeling that others do not respect one's religious beliefs), attributing unwanted events to demonic sources, and being unable to find a sense of ultimate meaning in life. In essence, spiritual struggles may be construed as a uniquely religious stressor. Although a number of studies suggest that spiritual struggles are associated with mental and physical health problems (e.g., Pargament, Koenig, Tarakeshwar and Hahn, 2001) there are still gaps in the literature. More specifically, researchers need to learn more about the factors that cause spiritual struggles to arise in the first place. Several potential causal factors have been identified in the literature including an insecure attachment to God (Ano and Pargament 2013), personality traits (e.g., neuroticism) (Wilt, Grubbs, Exline and Pargament 2015), the inability to forgive (AndersonMooney, Webb, Mvududu and Charbonneau, 2105), and the lack of humility (Grubbs and Exline 2014). However, these potential explanatory variables are largely psychological in nature and as a result, the potential influence of broad social factors has been largely overlooked. This paper focuses on a largely overlooked factor, socioeconomic status, and its relationship with spiritual struggles.

There are at least seven reasons why people in lower socioeconomic status (SES) groups may be more likely to experience spiritual struggles and the difficulties they create. First, research by 
Krause and Bastida (2011) reveals that greater financial difficulties are associated with less involvement in organized religion and a diminished sense of religious meaning in life. These results are relevant because, as we noted earlier, the inability to find a sense of meaning through religion is typically construed as one kind of spiritual struggle. However, whether financial difficulties are associated with other types of spiritual struggles has not been examined in the literature.

Second, research consistently reveals that lower SES individuals are more likely to experience a wide range of stressors than their upper SES counterparts (Adler and Snibbe 2003). This is important because research indicates that greater exposure to stress is associated with more spiritual struggles (Ellison, Roalson, Guillory, Flannelly and Marcum 2010; McCann and Webb 2012).

Third, even though the findings are equivocal, research reveals that lower SES social support networks may not function as effectively as the social support systems that are enjoyed by upper SES individuals (e.g., Airaksinen et al. 2015; Krause and Shaw 2000; Mickelson and Kubzansky 2003). Hobfoll's (1998) notion of the pressure cooker effect helps explain why this may be so. He begins by arguing that social networks tend to be homogeneous with respect to SES and as a result, if a focal person is experiencing economic problems, there is a good chance that their significant others are faced with the same difficulty. The resulting stress contagion that ripples through the social network is captured succinctly by Hobfoll (1998): "Since no one in the system is free of threat, individuals who themselves have a great need to depend on others must serve as supporters and loose precious resources that they themselves need at this time" (p. 208). The notion that there may be SES differences in social support is important because research have argued for some time that

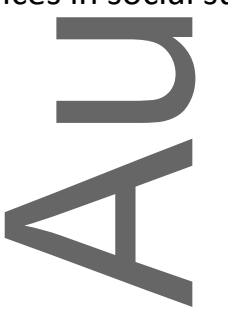

This article is protected by copyright. All rights reserved. 
significant others are an important resource for the development and maintenance of positive religious beliefs and behaviors (Berger, 1967).

Fourth, religious doubt is widely regarded as an important type of spiritual struggle (Exline, 2013). However, as research by Krause and Ellison (2009) suggests, religious doubt is neither inherently good nor inherently bad. Instead, the ways in which a person copes with doubt may determine whether doubt has a deleterious effect on health. The findings from their study suggest that suppressing feelings of doubt tends to erode health while seeing doubt as an opportunity for spiritual growth tends to bolster health. This distinction is important because Krause and Ellison (2009) report that lower SES people (as assessed by education) are more likely to suppress doubt whereas upper SES individuals are more likely to believe that doubt creates an opportunity for spiritual growth.

Fifth, people who experience ongoing economic problems, poor neighborhood conditions, and other related stressors may find it increasingly difficult to sustain the belief that God is benevolent and working for the best in their lives. This troubling state may manifest in feeling abandoned by God, which is a key marker of spiritual struggles.

Sixth, education is a key marker of socioeconomic status. This is important because research reveals that people with lower levels of educational attainment are more likely to attribute misfortune to demonic forces (Stark 2008). Cast within the context of our study, this suggests that lower SES people may attribute the oppressive economic conditions they face to demonic forces, which, as we note above, is another key dimension of spiritual struggles.

Seventh, lower SES people typically have fewer resources at their disposal for dealing with problems that arise in life (Mirowsky and Ross 2003a). Consequently, spiritual struggles discourage 
them from adopting sound religious coping strategies, thereby depriving them of one of the few resources they can access (i.e., religion).

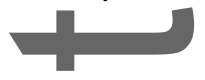

As the argument that has been provided up to this point suggests, the notion that spiritual struggles may be more prevalent in lower SES groups seems plausible. But the rationale we have presented so far does not do justice to the complex processes that may be at work. SES is a multidimensional construct in its own right and as a result, deeper insight into how SES may affect spiritual struggles warrants the use of more than one indicator of SES. Moreover, we have yet to fully illuminate the pathways that connect SES and spiritual struggles. Furthermore, since the literature on spiritual struggles was developed to understand variations in health, we have yet to explore the ways in which SES and spiritual struggles may influence this important outcome. It is for this reason that we developed and empirically evaluated a conceptual model to address these issues. This model is provided in the next section.

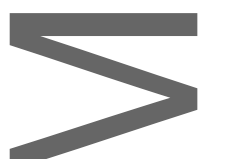

\section{SES, Spiritual Struggles, and Health}

The conceptual model that was developed for this study is presented in Figure 1. Two steps were taken to simplify the presentation of this complex theoretical scheme. First, the elements of the measurement model (i.e., the factor loadings and measurement error terms) are not shown in this diagram even though a full measurement model was estimated when this conceptual scheme was evaluated empirically. Second, the model in Figure 1 was assessed after the effects of age, sex, and race were controlled statistically (i.e., treated as exogenous variables).

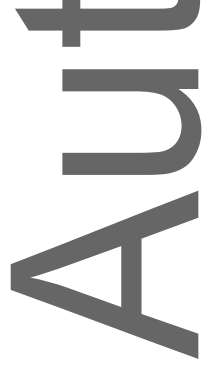

This article is protected by copyright. All rights reserved. 
$<$ Insert Figure 1 about here>

It should be emphasized that all of the paths in Figure 1 were estimated during the data analytic phase of this study (i.e., we estimated a fully saturated model). However, in order to keep the focus on the conceptual core, the discussion that is provided below is concerned solely with the linages that are bolded in Figure 1: (1) individuals with lower levels of educational attainment are more likely to encounter chronic economic difficulties; (2) people who experience ongoing financial strain are more likely to live in rundown neighborhoods; (3) people who live in dilapidated neighborhoods will be more angry than their well-to-do counterparts; (4) people who are more angry will, in turn, be more likely to experience spiritual struggles; and (5) greater spiritual struggles will be associated with more symptoms of physical illness. The theoretical rational for each of these hypotheses is provided below.

\section{Education and Financial Strain}

SES is often assessed with measures of education, occupation, and income. There are three reasons why we use education as the sole measure of socioeconomic status. First, in their insightful book on social status and health, Mirowsky and Ross (2003a) argue that, "Education is the key to one's place in the stratification system" (p. 30). They base their argument on the fact that education determines a person's subsequent occupation and income: “Education develops the habits and skills of communication: reading, writing, inquiring, discussing, looking things up, and figuring things out. It develops analytic skills of broad use such as mathematics, logic ..." (Mirowsky and Ross 2003a, p. 26). When these general skills are combined with occupational-specific training, it is not surprising to find that people who have a better education are more likely to find higher paying jobs (Mirowsky and Ross 2003a). 
The second reason why we rely on education has to do with the fact that researchers have known for some time that self-reports of income contain a substantial amount of measurement Tor example, error. For example, Crystal (1986) found that self-reports of income in the general population are under-reported by $15 \%$. He goes on to show that income among older adults was under-reported by $46 \%$.

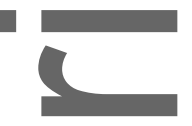

The third reason why we focus solely on education has to do with our study outcomehealth. People who are in poor health are likely to encounter more economic problems because of their physical chatlenges. In contrast, as we report below, the average age of the participant in our study is $50.7 \%$. This means that for many study participants, education was determined a good time prior to their current health.

Based on the decision to focus solely on education, we predict in Figure 1 that people with higher levels of educational attainment will be able to secure higher paying jobs and people with better jobs are, in turn, less likely to encounter financial problems across the life course (Schulz 2001).

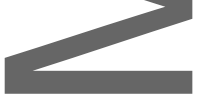

\section{Financial Strain and Neighborhood Deterioration}

Research consistently shows that people who encounter ongoing economic difficulties are more likely to live in neighborhoods that are dilapidated and rundown (Evans, Wethington, Coleman, Worms and Frongillo 2008; Krause 1993). This is important because living in rundown neighborhoods exposes people to a range of stressors including higher rates of crime (or greater

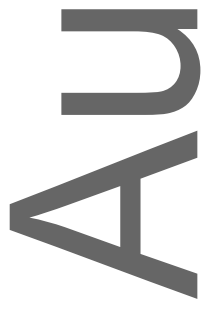

This article is protected by copyright. All rights reserved. 
concern over being a victim of a crime, Mirowsky and Ross 2003b), greater social isolation (Krause 1993), as well as stressors arising from air and noise pollution (Mirowsky and Ross 2003b). Research reveals that once people move into rundown neighborhoods, they are less likely to escape their residential problems by moving to better neighborhoods (South, Crowder and Chavez 2005). This suggests that like financial strain, neighborhood deterioration may also be thought of as a type of chronic or ongoing strain.

Specifying a causal link between chronic financial strain and neighborhood deterioration makes it possible to evaluate a principle that has been discussed in the stress literature for some time. As Wheaton (1994) argues, people are not randomly exposed to stressors over the course of their lives. Instead, his research indicates that some individuals tend to experience a series of different stressors over time, thereby demonstrating a tendency toward stress proneness. Finding a statistically significant relationship between financial strain and neighborhood deterioration in the current study would provide support for this perspective. However, one limitation in the work of Wheaton (1994) arises from the fact that he does not provide a clear sense of why some people are more likely to experience a series of stressful events. An effort is made in the current study to contribute to this literature by showing that stress proneness may arise from a person's socioeconomic standing (as reflected in low levels of respondent educational attainment) and the consequences that follow in its wake.

\section{Neighborhood Deterioration and Hostility}

Urban sociologists have argued for decades that the physical condition of a neighborhood serves as a lexicon that people rely on to evaluate the quality of the built environment. For example, Schorr (1970) maintains that housing represents an extension of oneself: it makes a statement to 
others about the nature and character of the resident. Schorr (1970) further proposes that housing can also affect the attitudes of the occupants - when dwellings are in poor condition, residents tend to become passive, pessimistic, and cynical. It follows from this that when a neighborhood is dominated by buildings, sidewalks, and roads that are in a state of disrepair, it will exude negative cues that foster a sense of mutual pessimism, cynicism, and mistrust among local residents. Empirical support for this perspective is provided by Ross and Mirowsky (2009), who report that people wholive in disadvantaged neighborhoods tend to feel powerless, threatened, and mistrustful of others (see also krause 1993). Moreover, Ross, Mmirowsky and Prebish (2001) found that rundown neighborhoods foster a sense of unfairness and injustice.

Although rundown neighborhoods may foster a range of negative emotions and negative attitudes, the model that was developed for the current study focuses on one emotion that may be especially important for research on the determinants of spiritual support - anger. Findings from several studies suggest that people who live in dilapidated neighborhoods tend to feel more angry (Schieman, Pearlin and Meersman 2006) and more hostile (Wen, Hawkley and Cacioppo 2006) than individuals who live in higher quality neighborhoods. However, these findings are far from new. One of the first studies in community psychiatry was conducted by Alexander Leighton and his colleagues (Hughes, Tremblay, Rapoport and Leighton 1960). They conducted detailed research in three different neighborhood environments, one of which was especially rundown. In addition to conducting quantitative research, these investigators sent teams of anthropologists into each area to evaluate the social environment. The team reports that people who lived in the dilapidated

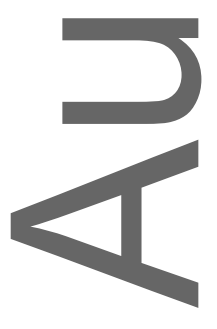

This article is protected by copyright. All rights reserved. 
community, ". . f find difficulties in family and community relationships and expect inconsistency of affection from their fellows. Meeting hostility from their nearest human contacts, they react in many situations with avoidance or antipathy" (Hughes et al. 1960, p. 250). The notion that living in impoverished neighborhoods may generate feelings of anger provides vivid insight into why Bradshaw and Ellison (2010) argue that lower SES people experience a range of emotions such as anger, resentment, shame, guilt, and anxiety.

\section{Anger and Spiritual Struggles}

In their widely-cited theory of anger, Spielberger and his colleagues identify a cluster of cognitive and behavioral outcomes that are associated with high levels of anger (Spielberger, Jacobs, Russell, and Crane, 1983). A number of these outcomes easily map onto spiritual struggles. For example, Spielberger et al. (1983) argue that angry people are easily frustrated, they tend to give up when faced with a challenging task, and they are less likely to come up with constructive problemsolving plans. Religion is clearly an abstract and complex phenomenon. In order to build and maintain their faith, people must come to grips with ambiguities, uncertainties, and beliefs that cannot be verified conclusively. Cast in terms of Spielberger's theoretical observations, one would expect to find that angry people will have difficulty developing constructive solutions to these difficulties. This is why we suspect that anger is likely to be associated with a key dimension of spiritual struggles - intrapsychic struggles (Pargament 2007). Consistent with this view, Ano and Pargament (2013) found higher trait anger among individuals with higher levels of spiritual struggles.

In their comprehensive review of the literature, Smith, Glazer, Ruiz and Gallo (2004) argue that people with high levels of anger and hostility possess negative views of themselves, as well as negative views of others and the relationships they maintain with them. As a result, angry and 
hostile persons are likely to create conflict with others that undermine their sources of support. Further evidence of these interpersonal problems may be found in studies which show that angry people are less forgiving (Lawler-Row, Karremans, Scott, Edis-Matityahou and Edwards 2008), they tend to be more alienated from others (Quinn, Rollock and Vrana 2014), and they are less likely to feel they belong (Palfai and Hart 1997). These insights are noteworthy because interpersonal difficulties with religious others is a widely regarded as a form of spiritual struggles (Pargament 2007).

\section{Spiritual Struggles and Health}

As research reviewed by Exline (2013) reveals, a growing number of studies indicate that spiritual struggles are associated with more physical health problems. There are at least four reasons why this may be so. First, spiritual struggles may be viewed as a type of religious stress. This is important because a vast literature suggests that greater exposure to stress is associated with more physical health problems (Tosevski and Milovancevic 2006; Schneiderman, Ironson and Siegel 2005). Second, research reviewed by Exline (2013) indicates that spiritual struggles are associated with more mental health problems. These findings are important because research consistently reveals that people who have more mental health problems also have greater physical health problems (Cohen and Rodriguez 1985; El-Gabalawy, Corey, Shooshtari and Sareen 2011). Third, spiritual struggles may have a direct physiological effect upon the body. More specifically, research reveals that spiritual struggles are associated with higher resting pulse rates (Krause, Ironson and Pargament 2016), higher levels of Interleukin-6 (a noxious proinflammatory cytocine) (Ai, Pargament, Kronfol,

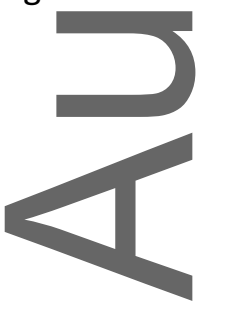

This article is protected by copyright. All rights reserved. 
Trice and Appel 2010), and an elevated CD4 count in patients with HIV/AIDS (Trevino, Pargament, Cotton, Leonard, Hahn, Caprini-Faigin and Tsevatg 2010). Fourth, research reveals that spiritual struggles are associated with addictive behaviors (Faigin, Pargament and Abu-Raiya 2014), which have obvious implications for health.

It is possible that health may affect spiritual struggles. For example, people who are in poor health may feel abandoned by God. Clearly longitudinal research is needed to address this issue. Unfortunately, there has been little longitudinal research on spiritual struggles and health. One of the few studies we were able to find reveals that low levels of spiritual struggles are associated with improvement over time in the health of patients with HIV/AIDS (Trevino et al. 2010). ${ }^{1}$

\section{Data and Methods}

\section{Sample}

The data for this study come from the Landmark Spirituality and Health Survey (LSHS), a nationwide face-to-face survey of adults age 18 and older who reside in the coterminous United States (i.e., residents of Alaska and Hawaii were excluded). This survey, which was completed in 2014, was conducted by the National Opinion Research Center (NORC). The NORC 2010 National Sampling Frame served as the basis for the sampling procedures. This sampling frame is based on

\footnotetext{
${ }^{1}$ The reader may wonder why more measures of religion were not included in our study model. There are two reasons for our choice of model specification. First, latent variable models contain a tightly integrated series of constructs in which each construct is associated with the constructs that come before and after it. Consequently, variables cannot merely be inserted into the model as one might do with a single ordinary least squares multiple regression equation. Instead, careful consideration must be given to how each construct fits into the overall conceptual scheme. Second, inserting new religion measures that are not associated with other constructs that are already in the model will lead to a deterioration in the fit of the model to the data, thereby calling into question the overall utility of a conceptual scheme
} 
two sources. First, the bulk of this data base comes from postal address lists that are compiled by the United States Postal Service (USPS). Second, field employees were sent to enumerate all house in areas where USPS address lists were unavailable. Sampling was done in three stages. First, National Frame Areas (NFAs) were constructed. In essence, NFAs are formed from pooling counties and metropolitan areas into blocks of designated sizes. A total of 44 NFAs were selected with probabilities proportional to size. Then, in the second stage, NFAs were partitioned into segments consisting of Census tracts and block groups. Segments were selected with probabilities proportional to size. In the third stage housing units were sampled with equal probabilities of selection within each segment and the occupants of these dwellings were recruited for the interviews.

The response rate for the study was 50 percent. The total number of completed interviews was 3,010. The sample was broken down into three age groups: $18-40(N=1,000), 41-64(N=1,002)$, and age 65 and older $(\mathrm{N}=1,008)$.

A total of 68 study participants self-identified as atheists. Consequently, they were excluded from the analyses provided below because the questions dealing with spiritual struggles were not administered to them. In addition, the procedures devised by Exline and her colleagues to measure spiritual struggles are used in the current study (Exline, Pargament, Grubbs and Yah 2014). Their protocol involves asking study participants to identify the most stressful experience they have encountered in the past 18 months. Following this, study participants are told to keep this event in mind as they answer the questions on spiritual struggles. A total of 707 study participants were excluded from the current study because they did not encountered a major stressor during this time.

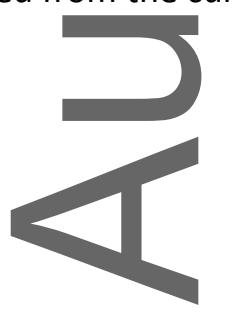

This article is protected by copyright. All rights reserved. 
The full information maximum likelihood (FIML) procedures was used to deal with item nonresponse. Consequently, complete data were available for 2,146 individuals.

\section{Measures}

Table 1 contains the observed indicators that were used to assess the latent constructs shown in Figure 1. The procedures that were used to code these items are provided in the footnotes of this table.

$$
\text { <Insert Table } 1 \text { about here> }
$$

Symptoms of Physical IIIness. Health was assessed with a ten item checklist of symptoms that are associated with physical illness. This measure was taken from the work of Magaziner, Bassett, Hebel, \& Gruber-Baldini (1996). A count was obtained of the number of symptoms that was experienced by study participants in the six months prior to the interview $(M=2.2 ; S D=2.3)$. A high score denotes more physical symptoms.

Education. Based on the insights provided by Mirowsky and Ross (2003), education serves as the primary measure of SES in our study. All study participants were asked to report the number of years of schooling they completed successively. Their responses were scored in a continuous format $(M=13.5 ; S D=3.1)$.

Financial Strain. Two indicators were taken from the work of Pearlin, Menaghan, Lieberman, and Mullan (1981) to assess ongoing economic problems. A high score on these items denotes greater financial strain $(M=3.7 ; S D=1.6)$.

Neighborhood Conditions. Ten indicators that come from research by Krause (1993) were used to assess the overall neighborhood environment of study participants. Five items assess the 
state of the respondent's own home while five items measure the overall condition of the neighborhood outside the respondents' homes. The neighborhood ratings were completed by the interviewers, and not the respondent. This is important because as research reveals, it avoids bias that arises when study participants are asked to rate their own homes and their own neighborhoods (Winkel, Saegert and Evans 2009). For example, research consistently reveals that living in rundown neighborhoods is associated with depression (e.g., Richardson et al. 2015). As we reported earlier, mental and physical health problems are often comorbid (El-Gabalawy et al. 2011). Consequently, asking depressed people to rate their own neighborhoods would result in overly negative assessments, thereby biasing the relationship between neighborhood conditions and physical health.

It is somewhat unusual in latent variable models to have 10 observed indicators of a single latent construct. So in order to simplify the model estimation process, we used the parceling procedure (for a discussion of this procedure, see Kline 2005). This means that the five indicators that assess the quality of the respondent's own home were added together to form a single summary measure. Similarly, the five items that measure the external neighborhood were added to form a single summary measure. Following this, the two summary scales were used as observed indicators of the latent construct that reflects overall neighborhood conditions. As Kline (2005) points out, measures that are based on the parceling technique have the added advantage of being more reliable (more will be said below about the reliability of the measures in this study).

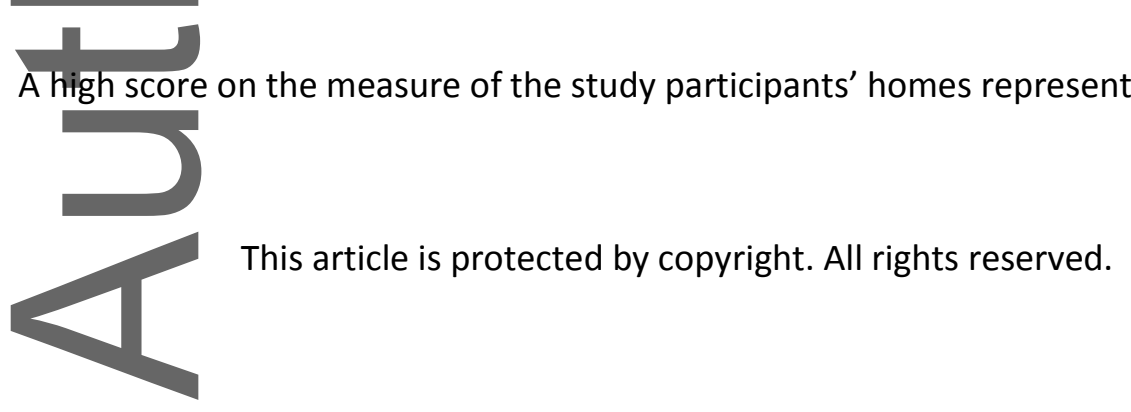


conditions $(M=9.6 ; S D=4.0)$. The same is true for the measure of external neighborhood conditions $(M=9.8 ; S D=3.6)$.

Anger. Anger was measured with five indicators that come from the widely-used scale that was developed by Cook and Medley (1954). A high score on these observed indicators stands for greater anger and cynical hostility $(M=15.7 ; S D=4.3)$. The items we selected largely reflect skepticism about the intentions of others. These indicators are consistent with the qualitative findings by Hughes et al. (1960) that were discussed earlier.

Spiritual Struggles. Spiritual struggles were assessed with a shortened 15 -item version of the Religious and Spiritual Struggles (RSS) Scale that was developed by Exline, Pargament, Grubbs and Yah (2014). Once again, parceling was used to create five summary measures of each of the following types of spiritual struggles: divine, demonic, interpersonal, moral or intrapsychic struggle, and ultimate-meaning. The overall mean of the summary spiritual struggles scale was $21.9(S D=8.5)$. A high score denotes greater spiritual struggles.

Demographic Control Variables. The relationships among the variables that were discussed above were evaluated after the effects of the following demographic control variables were controlled statistically: age $(M=50.7 ; S D=18.7)$, sex $(1=$ men; $0=$ women $)(41.3 \%$ men $)$, and race $(1$ $=$ Black; 0 = otherwise $)(16.4 \%$ Black $)$.

\section{Results}

The findings from the current study are presented below in four sections. Some technical issues involving the estimation of the study model are reported in the first section. Reliability estimates for the multiple item constructs are provided in section two. Section three contains the 
substantive findings that emerged from estimating the study model. Section four contains some supplementary analyses that have not been discussed up to this point.
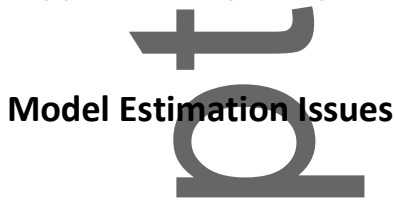

The model in Figure 1 was evaluated with the maximum likelihood estimator in Version 8.80 of the LISREL statistical software program (du Toit and du Toit 2001). Use of this estimator is based on the assumption that the observed indicators have a multivariate normal distribution. Preliminary tests (not shownhere) indicated that this assumption had been violated in the current study. Although researchers have devised a number of strategies for dealing with departures from multivariate normality, the straightforward approach that is discussed by du Toit and du Toit (2001) was implemented in this study. These investigators report that departures from multivariate normality can be handled by converting raw scores on the observed indicators to normal scores prior to estimating the model (du Toit and du Toit 2001, p.143). Consequently, the analyses presented below were performed with observed indicators that were normalized.

Because the FIML procedure was used to deal with item non-response, the LISREL software program provides only two goodness-of-fit measures. The first is the full information maximum likelihood chi-square value (619.404 with 121 degrees of freedom, $p=.001)$. Unfortunately, this statistic is not very useful because it substantially underestimates the fit of the model to the data when samples are large, such as the sample in the current study. Better insight into the fit of the model to the data is provided by the second goodness-of-fit measure - the root mean square error of approximation (RMSEA). The RMSEA value for the model in Figure 1 is .043. Researchers have yet to

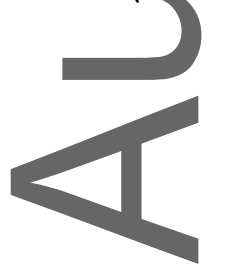

This article is protected by copyright. All rights reserved. 
agree on an RMSEA cut point score for identifying a satisfactory fit of the model to the data.

However, many investigators follow the recommendations of Hu and Bentler (1999), who argue that values below .05 indicate a good fit. Based on this criteria, we conclude that the fit of our model to the data is good.

\section{Reliability Estimates}

The factor loadings and measurement error terms that were derived from estimating the study model are presented in Table 2 . These coefficients are important because they provide preliminary information about the reliability of the observed indicators that are used to measure the multiple item latent constructs. Widaman (2012) proposes that items with standardized factor loadings in excess of .600 tend to have good reliability. The data in Table 2 indicate that the standardized factor loadings range from .507 to .902 . Three factor loadings were below the cut point set by Widaman (2012). However, the difference between these estimates and Widaman's (2012) recommendation are largely trivial.

$<$ Insert Table 2 about here>

Even though the factor loadings and measurement error terms that are associated with the observed indicators provide useful information about the reliability of each item, it is also good to obtain reliability estimates for the scales as a whole. DeShon (1998) provides a formula that can be used to compute these estimates. This formula is based on the factor loadings and measurement error terms in Table 2. Applying the formula provided by DeShon (1998) to these data yields the following reliability estimates for the multiple item constructs in Figure 1: financial strain (.764), neighborhood conditions (.881), anger (.817), and spiritual struggles (.755). Taken together, the data provided in this section suggest that the reliability of the multiple-item study measures is good. 


\section{Substantive Findings}

The substantive findings that were derived from estimating the relationships among the latent constructs in Figure 1 are provided in Table 3. Taken as a whole, these data tend so support the hypotheses that were developed for this study. The findings in Table 3 indicate that study

口 participants with lower levels of educational attainment tend to experience more financial strain $(\beta=$ $-.292 ; p<.001)$. The data further reveal that respondents who encounter greater financial strain are more likely to reside in rundown neighborhoods $(\beta=.269 ; p<.001)$. This is important because, as we hypothesized earlier, the results suggest that people who live in dilapidated neighborhoods tend to be more angry $(\beta=109 ; p<.001)$. The data in Table 3 reveal that people who are more angry tend to encounter more spiritual struggles $(\beta=.217 ; p<.001)$. And as several other studies have shown, greater spiritual struggles are associated with more symptoms of physical illness $(\beta=.171 ; p<.001)$.

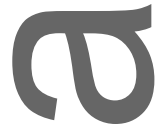
<Insert Table 3 about here>

Viewedmore broadly, the constructs that were used to assess SES in Figure 1 explain 19.7\% of the variance in spiritual struggles. In addition, the constructs in Figure 1 explain $20.4 \%$ of the variance in symptoms of physical illness.

Latent variable modeling procedures are important because they provide two closely related benefits that are not found in many other estimation procedures. First, the results that have been presented up to this point (e.g., the relationship between education and financial strain) are direct effects. However, latent variable modeling procedures also provide the indirect and total effects that

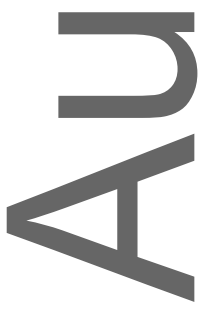

This article is protected by copyright. All rights reserved. 
operate through a study model. The second benefit follows from the first. Sometimes it is possible to use the direct, indirect, and total effects to clarify unanticipated study findings. Partitioning study findings into direct, indirect, and total effects is sometimes referred to in the literature as the decomposition of effects (e.g., Little 2013). Three decompositions are provided below. However, before turning to these analyses, it is important to clarify the meaning of indirect and total effects.

Recall the education is used in Figure 1 as our primary measure of SES. One of the major goals of this study is to see if SES is associated with spiritual struggles. According to the data in Table 3, education does not appear to be significantly related to spiritual struggles $(\beta=-.007 ; n$ s.). But this direct effect does not adequately reflect what our model is capable of revealing because education affects spiritual struggles indirectly through financial strain, rundown neighborhoods, and anger. This means, for example, that education is associated with financial strain, and financial strain is, in turn related to spiritual struggles. Adding the direct effect of education on spiritual struggles with the indirect effects that operate through financial strain, neighborhood conditions, and anger yields the total effect of education on spiritual struggles. The total effect is important because it provides a better vantage point for assessing the overall influence of SES in our study model.

The first decomposition that will be reviewed here is based on the example provided above. As we just discussed, the direct effect of education on spiritual struggles in Table 3 may initially create the initial impression that SES is not associated with religious difficulties ( $\beta=-.007 ; n s)$. But when this direct effect is added to the indirect effects that operate through financial strain, neighborhood conditions, and anger ( $\beta=-.152 ; p<.001$; not shown in Table 3$)$, the resulting total effect ( $\beta=-.159 ; p<.001$; not shown in Table 3 ) suggests that this conclusion would have been erroneous. The fact that the direct effect of education is not significant while the indirect effects are 
significant suggests that our model fully explains why lower SES people are more likely to experience spiritual struggles.

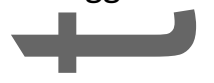

Given the central role that SES plays in our analyses, the second decomposition also deals with this important social structural construct. A vast literature suggests that lower SES individuals

-

tend to experience more physical health problems than their well-to-do counterparts (Adler and Snibbe 2003), yet the direct effect in Table 3 appear to indicate that SES is only weakly associated with health $(\beta=-068 ; p<.001)$. But once again, the picture changes after the indirect and total effect of education on symptoms of physical illness are taken into account. More specifically, the data indicate that the indirect effects of education on health that operate through financial problems, neighborhood conditions, anger, and spiritual struggles are statistically significant $(\beta=-$ $.131 ; p<.001 ;$ not shown in Table 3). When the direct and indirect effects are summed, the resulting total effect brings the relationship between education and health more in line with previous research $(\beta=-.191 ; p<.001 ;$ not shown in Table 3$)$.

The third decomposition involves a construct that has not been discussed up to this point. A number of studies suggest that Blacks tend to experience higher levels of anger than Whites (e.g., Boylan, Lewis, Coe and Ryff 2015). This is typically viewed as a common response to economic inequality. The data in Table 3 suggest that Blacks tend to be higher in angry than members of other ethnic and racial groups $(\beta=.128 ; p<.001)$. But an analysis of the indirect effects of race that operate through the study model indicate that the magnitude of this relationship is underestimated by the direct effect. When the indirect effects of race that operate through the study model $(\beta=$

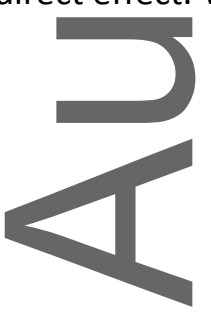

This article is protected by copyright. All rights reserved. 
$.065 ; p<.001 ;$ not shown in Table 3 ) are added to the direct effect, the resulting total effect of race on anger $(\beta=.193 ; p<.001 ;$ not shown in Table 3$)$ is approximately $51 \% \operatorname{larger}((193-.128) / .128=$ $.507)$.

\section{Supplementary Analysis}

Anger occupies a key place in our conceptual model because we view it as a potentially important determinant of spiritual struggles. However, when the measures that are used to assess spiritual struggles are examined, a potential problem arises. More specifically, the first indicator that is used to measure divine struggles deals with feeling angry at God while the first indicator that is used to assess interpersonal struggles reflects feeling angry at organized religion. This raises the possibility that out measure of anger is confounded with the measures of divine and interpersonal struggles. We re-estimated the model after dropping divine struggles and interpersonal struggles from the analysis. This left three dimensions of spiritual struggles in the model: supernatural evil, intrapsychic struggles, and crises of ultimate meaning. The findings indicate that anger is still significantly associated with these three dimensions of spiritual struggles $(\beta=.191 ; p<.001)$, thereby providing some evidence that anger and spiritual struggles are not confounded.

\section{Discussion and Conclusions}

Charles Horton Cooley was a towering figure in the development of sociology as an academic discipline. In his view, social class standing exerted a profound influence on human behavior: "There is nothing more important to understand, or less understood, than the class atmosphere in which nearly all of us live" (Cooley 1902/2003, p. 72). Based on these long standing insights, we set out to explore the influence of SES on spiritual struggles. The conceptual model that we developed and evaluated empirically provides support for the following linkages: (1) people with 
lower levels of educational attainment are more likely to encounter financial difficulties; (2) individuals who are confronted by economic problems are more likely to live in rundown neighborhoods; (3) living in dilapidated neighborhoods makes people angry; (4) those who are more angry tend to experience more spiritual struggles; and (5) greater spiritual struggles are associated with more symptoms of physical illness. As the decomposition involving education revealed, these linkages fully explain the relationship between this key marker of SES and spiritual struggles.

There are three reasons why the findings from our study are noteworthy. First, this is one of the first studies to assess the influence of SES on spiritual struggles. Second, we examined this relationship with data from a recent nationally representative sample. Third, rather than merely assessing the direct effect of SES on spiritual struggles, we examined the interplay between three different components of SES and showed how they affect anger, which serves to heighten the tribulations that people encounter with their faith.

Even though we explored some previously unexamined issues, a considerable amount of research remains to be done. Further research is needed in at least four areas. First, more work is needed fully explain how lower SES standing affects anger. For example, at several points in the development of our conceptual model we noted that economic problems may create interpersonal difficulties in lower SES social networks (e.g., the pressure cooker effect, Hobfoll 1998). We suspect these interpersonal difficulties are a potent source of anger, as well. Unfortunately, we do not have measures of negative interaction in our data. Examining this issue should be a high priority in the future.

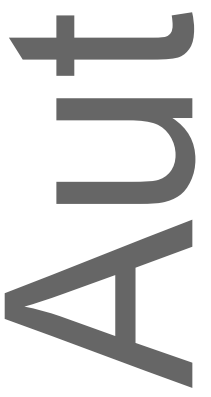

This article is protected by copyright. All rights reserved. 
Second, as research by Krause (2011) and many others reveals, parental education is a strong determinant of a respondent's own education. Including parental education in our model would make it possible to test an intriguing possibility. Perhaps parental education serves as a vehicle for the intergenerational transmission of spiritual struggles. Once again, we were unable to examine this issue empirically because we do not have a measure of parental education in our data.

Third, our study focuses solely on the detrimental aspects of lower SES life. However, researchers have long been aware of the fact that lower SES individuals have several key sources of resilience, as well. One source of resilience may be the close social relationships they develop in religious institutions (Krause 2008). Clearly, a more complete understanding of the relationship between SES and spiritual struggles must involve the ways in which sources of resilience as well as sources of distress shape the ways in which people view their faith.

Fourth, in order to properly gauge the relative importance of neighborhood conditions in the genesis of spiritual struggles it would be useful to compare and contrast the effects of neighborhood conditions with the effects of other well-known correlates. One such correlate is personality traits. For example, as we noted earlier, Wilt, Grubs, Exline, and Pargament (2016) report that higher levels of neuroticism are associated with more difficulties with spiritual struggles.

In the process of exploring additional issues, researchers should also address the three shortcomings in our work. First, our data were gathered at a single point in time and as a result, the "causal" ordering among the constructs in our conceptual model were based on theoretical considerations alone. We specified, for example, that anger promotes spiritual struggles, but other investigators might maintain that spiritual struggles foster more anger. Similarly, we specified that spiritual struggles affect health but one might argue that people who are in more health might feel 
they have been abandoned by God (i.e., a form of spiritual struggles). Clearly this as well as other causal assumptions in our conceptual model should be evaluated with data that have been gathered at more than one point in time.

Second, our measure of anger is somewhat limited. As we noted earlier, our indicators<smiles>[CH]=C</smiles>

reflect skepticism about the intentions of others. However, as other studies in the field indicate, angry people may yell at significant others more often and enter into disagreements with them more frequently. A full slate of anger items will likely provide greater insight into the relationship between neighborhood conditions and hostility.

Third, as we reported earlier, 707 study participants who did not experience a stressful event were excluded from our analyses. It is possible that excluding the data that was provided by these individuals biased our study findings in some way. Unfortunately, it is not possible to assess the extent of this problem without additional data.

Some practical applications arise from the findings in our study. A number of studies reveal that providing counseling to people who are in the midst of spiritual struggles can improve their mental health (e.g., Murray-Swank and Pargament 2008). The findings from our study suggest that it may be important to take a broader social structural approach into consideration in these therapeutic sessions. Helping people grapple with the anger that arises from financial problems and living in a rundown neighborhood may be an important point of departure in this respect.

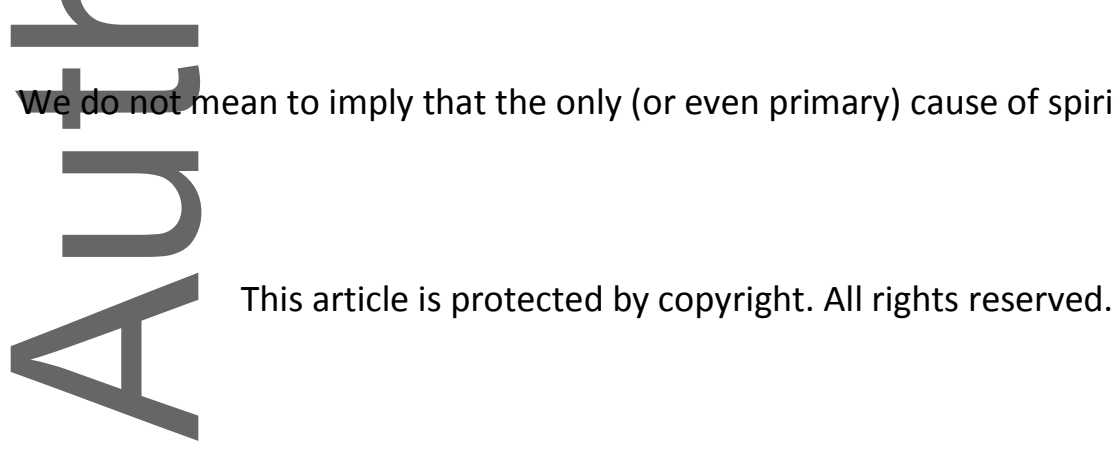


Instead, we suspect a number of factors come into play including genetic and psychological influences. Even so, by bringing SES to the foreground, our intent was to redress the psychological emphasis in research on spiritual struggles and call attention to truly multi-disciplinary nature of this important facet of religious life.

\section{References}

Adler, Nancy E. And Alana Conner Snibbe. 2003. The role of psychosocial processes in explaining the gradient between socioeconomic status and health. Current Directions in Psychological Science 12(4):119-123.

Ai AmyL. Kenneth I. Pargament, Ziad Kronfol, Terrence N. Tice and Hoa Appel. 2010. Pathways to postoperative hostility in cardiac patients: Mediation of coping, spiritual struggle and Interleukin-6. Journal of Health Psychology 15(2):186-195.

Airaksinen, Jaakko, Marko Elovainio, Terho Lehtimaki, Olli Raitakari, Lisa Keltikangasa-Javinen and Markus Jokela, 2015. Neighborhood effects on depressive symptoms, social support, and mistrust: Longitudinal analysis with repeated measurements. Social Science and Medicine 136-137 (7):10-16.

Anderson-Mooney, Amelia J., Marcia Webb, Nyaradzo Mvududu, and Anna M. Charbonneau. 2015. Dispositional forgiveness and meaning-making: The relative contributions of forgiveness and adult attachment style to struggling or enduring with God. Journal of Spirituality and Mental Health 17(2):91-109.

Ano, Gene C. and Kenneth I. Pargament. 2013. Predictors of spiritual struggles: An exploratory study. Mental Health, Religion \& Culture 16(4):419-434. 
Berger, Peter L. 1967. The sacred canopy: Elements of a sociological theory. New York: Doubleday.

Boyan, Jennifer Morozink, Tene T. Lewis, Christopher L. Coe and Carol D. Ryff. 2015. Educational status, anger, and inflammation in the MIDUS national sample: Does race matter? Annals of Behavioral Medicine 49(4):570-578.

(

1

Bradshaw, Matt and Christopher G. Ellison. 2010. Financial hardship and psychological distress:

Explaining the stress buffering effects of religion. Social Science and Medicine 71(2): 196-

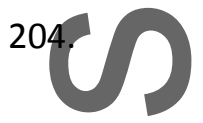

Cohen, Sheldon and Mario S. Rodriguez. 1995. Pathways linking affective disturbances and physical disorders. Health Psychology 14(5):374-380.

Cook, Walter W. and Donald M. Medley. 1954. Proposed hostility and Pharisaic-virtue scales for the MMPI. Journal of Applied Psychology 39(2):123-129.

Cooley, Charles Horton. 1902.2003. Human nature and the social order. New Brunswick NJ:

Transaction Publishers.

Crystal, Stephen. 1986. Measuring income and inequality among the elderly. The Gerontologist

26(1):56-59.

DeShon, Richard P. 1998. A cautionary note on measurement error corrections in structural equation models. Psychological Methods 3(4):412-423.

du Toit, Mathilda and Stephen du Toit. 2001. Interactive LISREL: User's guide. Lincolnwood, IL:

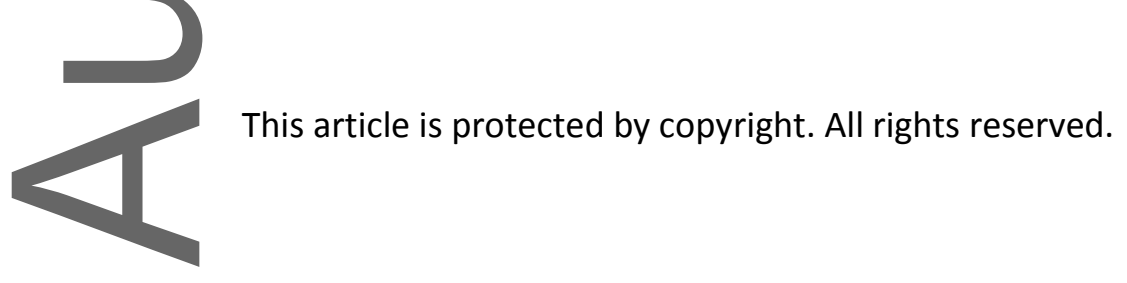


Scientific Software International.

El-Gabalawy, Renee, Corey S. Mackenzie, Shahin Shooshtari and Jitender Sareen. 2011. Comorbid health conditions and anxiety disorders: A population-based exploration of the prevalence and health outcomes of older adults. General Hospital Psychiatry 33(6):556-564.

Ellison, Christopher G., Lori A. Roalson, Janelle M. Guillory, Kevin. J. Flannelly, and Jack P. Marcum. 2010. Religious resources, spiritual struggles, and mental health in a nationwide sample of Presbyterians. Pastoral Psychology 59 (2):287-304.

Exline, Julie J. 2013. Religious and spiritual struggles. In APA handbook of psychology, religion, and spirituality, Vol. 1, edited by Kenneth I. Pargament, pp. 459-476. Washington DC: American Psychological Association.

Exline, Julie J., Kenneth I. Pargament, Joshua B. Grubbs and Ann Marie Yah. 2014. The Religious and Spiritual Struggles Scale: Development and initial validation. Psychology of Religion and Spirituality 6(3):208-222.

Evans, Gary W., Elaine Wethington, Meredith Coleman, Margo Worms and Edward A. Frongillo. 2008. Income inequalities among older persons: The mediating role of multiple risk exposures. Journal of Aging and Health 20(1):107-125.

Faigin, Carol Ann, Kenneth I. Pargament and Hisham Abu-Raiya. 2014. Spiritual struggles as a possible risk factor for addictive behaviors: An initial empirical investigation. International Journal for the Psychology of Religion 24(3):201-214.

Grubbs, Joshua B. and Julie J. Exline. 2014. Humbling yourself before God: Humility as a reliable predictor of lower diving struggles. Journal of Psychology and Theology 42(2):41-49. 
Hobfoll, Stevan E. 1998. Stress, culture, and community: The psychology and philosophy of stress.

New York: Plenum.

Trats

Hu, Li-Tze and Peter M. Bentler. 1999. Cutoff criteria for fit indexes in covariance structure analysis.

Conventional criteria versus alternatives. Structural Equation Modeling 6(1):1-55.

맘

Hughes, Charles C., Marc-Adelard Tremblay, Robert N. Rapoport and Alexander H. Leighton. 1960.

The people of Cove and Woodlot. New York: Basic Books.

Kline, Rex B. 2005. Principles and practice of structural equation modeling, $2^{\text {nd }}$ edition. New York:

Guilford.

Krause, Neat. 1993. Neighborhood deterioration and social isolation in late life. International

International Journal of Aging and Human Development 36(1):9-38.

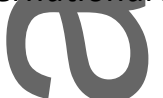

Krause, Neal. 2011. Neighborhood conditions and helping behavior in late life. Journal of

Environmental Psychology 31(1):62-69.

Krause, Neal and Elena Bastida. 2011. Financial strain, religious involvement, and life satisfaction among older Mexican Americans. Research on Aging 33(4):403-425.

Krause, Neal and Christopher G. Ellison. 2009. The doubting process: A longitudinal study of the precipitants and consequences of religious doubt in older adults. Journal for the Scientific

Study of Religion 48(2):293-312.

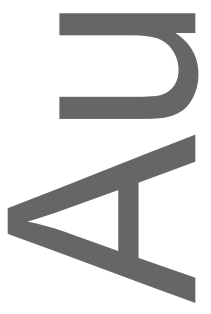

This article is protected by copyright. All rights reserved. 
Krause, Neal and Benjamin A. Shaw. 2000. Giving social support to others, socioeconomic status, and changes in self-esteem in late life. Journal of Gerontology: Social Sciences 55B(6):S323-S333.

Krause, Neal, Kenneth I. Pargament, Gail Ironson and R. David Hayward. 2016. Spiritual struggles and Interleukin-6: Assessing the potential costs and benefits. Unpublished manuscript.

Lawler-Row, Kathleen A., Karremans, Johan C., Scott, Cynthia, Meirav Edis-Matityahou and Laura Edwards. 2008. Forgiveness, physiological reactivity and health: The role of anger. International Journal of Psychophysiology 68(1):51-58.

Little, Todd D. 2013. Longitudinal structural equation modeling. New York: Guilford.

Magaziner, Jay, Susan S. Bassett, Hebel, J. Richard and Ann L. Cruber-Baldini. 1996. Use of proxies to measure health and functional status in epidemiologic studies of community dwelling women age 65 years and older. American Journal of Epidemiology 143(3):283-290.

McCann, Russell A. and Marcia Webb. 2012. Enduring and struggling with God in relation to traumatic symptoms: The mediating and moderating roles of cognitive flexibility. Psychology of Religion and Spiritualty 4:143-153.

Mirowsky, John and Cathrine E. Ross. 2003a. Education, social status, and health. New York:

Aldine De Gruyter. Mirowsky, John and Catherine E. Ross. 2003b. Social causes of psychological distress, $2^{\text {nd }}$ edition. New York: Aldine De Gruyter.

Murray-Swank, Nichole A. and Kenneth I. Pargament. 2008. Solace to the soul: Evaluating a Spiritually integrated counseling intervention for sexual abuse. Counseling and Spirituality 27(2):157174. 
Palfai, Tibor and Kenneth M. Hart. 1997. Anger coping styles and perceived social support. Journal of Social Psychology 137(4):405-411.<smiles>C1CC2CC12</smiles>

Pargament, Kenneth I. 2007. Spiritually integrated psychotherapy: Understanding and addressing the sacred. New York: Guilford.

a

Pargament, Kenneth I., Harold G. Koenig, Nalini Tarakeshwar and June Hahn. 2001. Religious struggle as a predictor of mortality among medically ill elderly patients: A 2-year longitudinal study. Archives of Internal Medicine 161:1881-1885.

Pargament, Kenneth I., Nichole A. Murray-Swannk, Gina M. Magyar and Gene G. Ano. 2005. Spiritual struggle: A phenomenon of interest to psychology and religion. In Judeo-Christian perspectives on psychology: Human nature, motivation, and change. Edited by William R. Miller and Harold D. Delaney, pp. 245-268.

Pearlin, Leonard. I., Elizabeth G. Menaghan, Moron A. Lieberman, and John T. Mullin. 1981. The stress process. Journal of Health and Social Behavior 22(4):337-356.

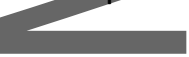

Quinn, Cathleen A., David Rollock and Scott R. Vrana. 2014. A test of Spielberger's state-trait theory of anger with adolescents: Five hypotheses. Emotion 14(1):74-84.

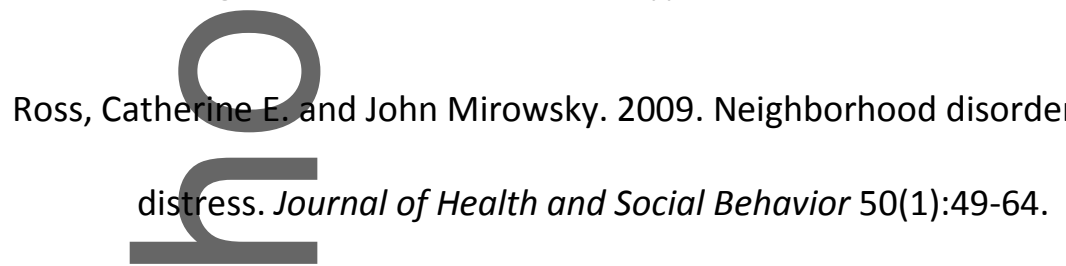

Ross, Catherine E., John Mirowsky and Shana Prebish. 2001. Powerlessness and the amplification of

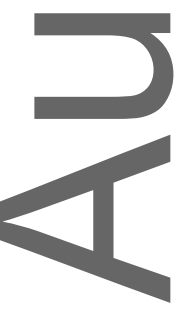

This article is protected by copyright. All rights reserved. 
threat: Neighborhood disadvantage, disorder and mistrust. American Sociological Review 66:568-591.

Schieman, Scott and Leonard I. Pearlin. 2006. Neighborhood disadvantage and anger among older adults: Social comparisons and effect modifiers. Journal of Health and Social Behavior 47(2):156-172.

Schneiderman, Neil, Gail Ironson and Scott D. Siegel. 2005. Stress and health: Psychological, behavioral, and biological determinants. Annual Review of Clinical Psychology 1(1):607-628.

Schorr, Adam L. 1970. Housing and its effects. In Neighborhood, city, and metropolis: An integrated reader in urban sociology, edited by Robert Gutman and David Popenoe, pp. 107-143. New York: Random House.

Schulz, James H. 2001. The economics of aging, $7^{\text {th }}$ edition. Westport CT: Auburn House.

Smith, Timothy W., Kelly Glazer, John M. Ruiz and Linda C. Gallo. 2004. Hostility, anger, aggressiveness and coronary heart disease: An interpersonal perspective on personality, emotion, and health. Journal of Personality 72(6):1217-1270.

South, Scott J., Kyle Crowder and Erick Chavez. 2005. Exiting and entering high-poverty neighborhoods: Latinos, Blacks and Anglos compared. Social Forces 84(2):873-900.

Stark, Rodney. 2008. What Americans really believe. Waco, TX: Baylor University Press.

Tosevski, Dusica and Milica Pejovic Milovancevic. 2006. Stressful life events and physical health. Current Opinion in Psychiatry 19(2):184-189.

Trevino, K. M., Kenneth I. Pargament, Sian Cotton, Anthony C. Leonard, June Hahn, Carol Ann 
Caprini-Faigin and Joel Tsevat. 2010. Religious coping and physiological, psychological, social and spiritual outcomes in patients with HIV/AIDS: Cross-sectional and longitudinal findings. AIDS Behavhior 14(2):379-389.

Wen, Ming, Louise C. Hawkley and John T. Cacioppo, 2006. Objective and perceived neighborhood environment, individual SES and psychosocial factors and health: An analysis of older adults in Cook County, Illinois. 2006. Social Science and Medicine 63(10):2575-2590.

Wheaton, Blair. 1994. Sampling the stress universe. In Stress and mental health: Contemporary Issues and prospects for the future, edited by William R. Avison and lan H. Gottlieb, pp. 77114. New York: Plenum.

Widaman, Keith F. Exploratory factor analysis and confirmatory factor analysis. 2012. In APA handbook of research methods in psychology, Vol. 3: Data analysis and research publication, edited by Harris Cooper, pp. 361-389. Washington DC: American Psychological Association.

Wilt, Joshua A., Joshua B. Gruggs, Julie J. Exline and Kenneth I. Pargament. 2016. Personality, religious and spiritual struggles, and well-being. Psychology of Religion and Spirituality. Advance Online. July, 2015.

Winkel, Gary, Susan Saegert and Gary W. Evans. 2009. An ecological perspective on theory, methods, and analysis in environmental psychology: Advances and challenges. Journal of Environmental Psychology 29(3):318-328.

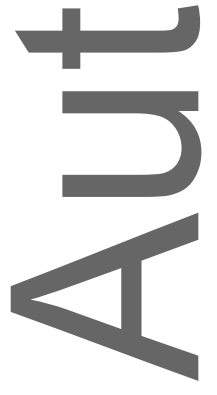

This article is protected by copyright. All rights reserved. 
Figure Caption

Figure 1. A Conceptual Model of Socioeconomic Status, Spiritual Struggles, and Health ${ }^{\mathrm{a}}$

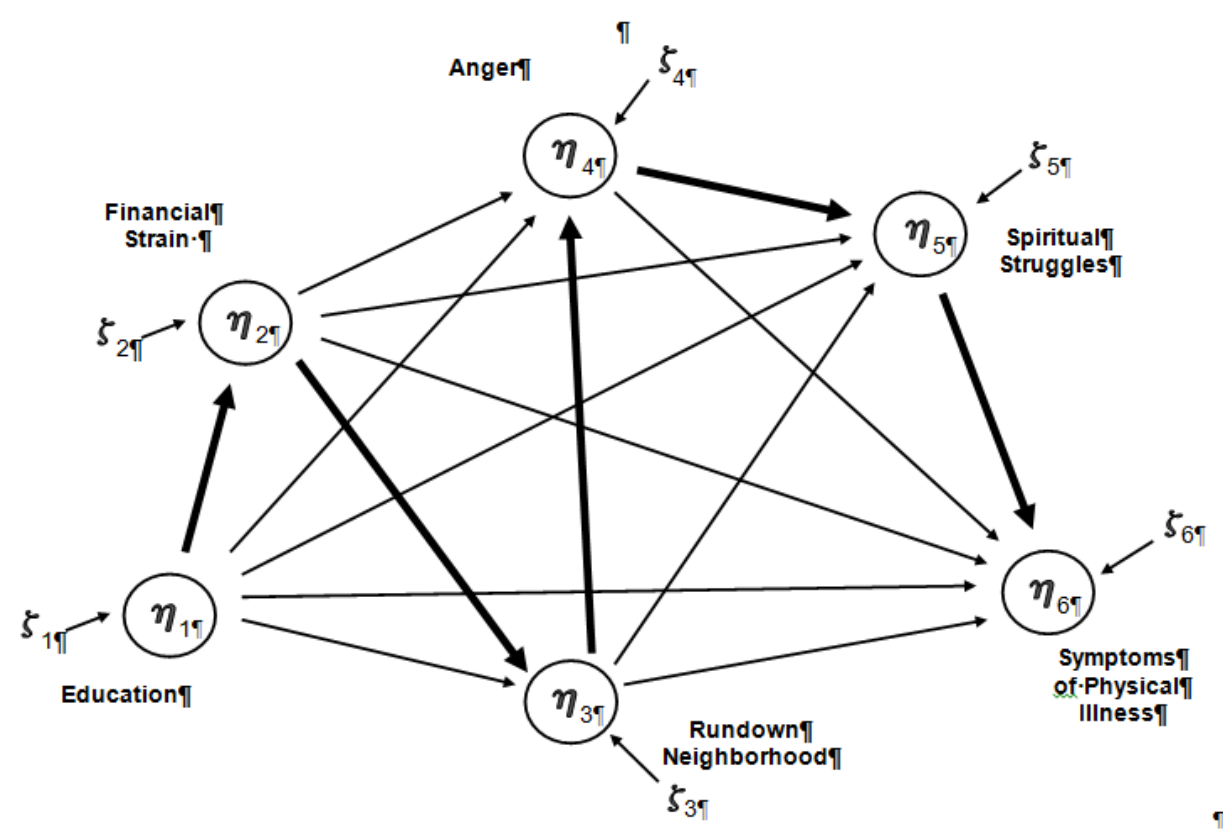

a These relationships were assessed after the effects of age, sex, and race were controlled statistically.

Table 1. Core Study Measures

1. Symptoms of Physical IIIness ${ }^{a}$

A. Frequent cramps in the legs

B. Pains in the heart or tightness or heaviness in the chest 
C. Trouble breathing or shortness of breath

D. Swollen ankles

E. Pains in the back or spine

F. Repeated pains in the stomach

G. Frequent headaches

H. Constant coughing or frequent heavy chest colds

I. Stiffness, swelling or aching in any joint or muscle

J. Getting very tired in a short time

K. Dizziness or nausea

2. Educational Attainment (years of completed schooling)

3. Financial Strain

A. How much difficulty do you have meeting your monthly payments on bills? ${ }^{b}$

B. In general. How do our finances usually work out at the end of the month?

4. Neighborhood Conditions

A. Condition of Study Participant's Home - Sum of the following items ${ }^{d}$

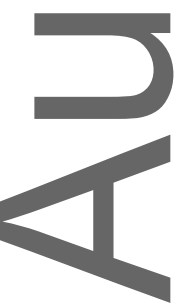

This article is protected by copyright. All rights reserved. 
1. Neatness and cleanliness of the inside of the building

2. The physical condition of the interior - the walls, ceiling, floor, etc.

3. The furnishings - the furniture, carpets, appliances, TV, etc

4. The condition of the outside of the dwelling (including the halls and lobby if an apartment building)

5. Overall, how would you describe the dwelling

B. Conditions Outside the Study Participant's Home - Sum of the following items ${ }^{d}$

1. The condition of other houses and buildings in the neighborhood

2. The amount of noise from traffic, trains, airplanes, industry, and things like that

3. The quality of the air - amount of pollution, dirt, and fumes in the air

4. Condition of roads in the neighborhood

5. Condition of the yards and sidewalks in front of the structures in the neighborhood

\section{Anger}

A. I think most people lie to get ahead.

B. Most people make friends because friends are likely to be useful to them

C. Most people will use somewhat unfair means to gain profit or an advantage rather than lose it. 
D. Most people inwardly dislike putting themselves out to help other people.

E. I commonly wonder what hidden reason another person may have for doing something

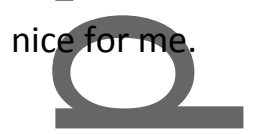

\section{Spiritual Struggles}

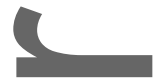

A. Divine Struggles - the sum of the following items ${ }^{f}$

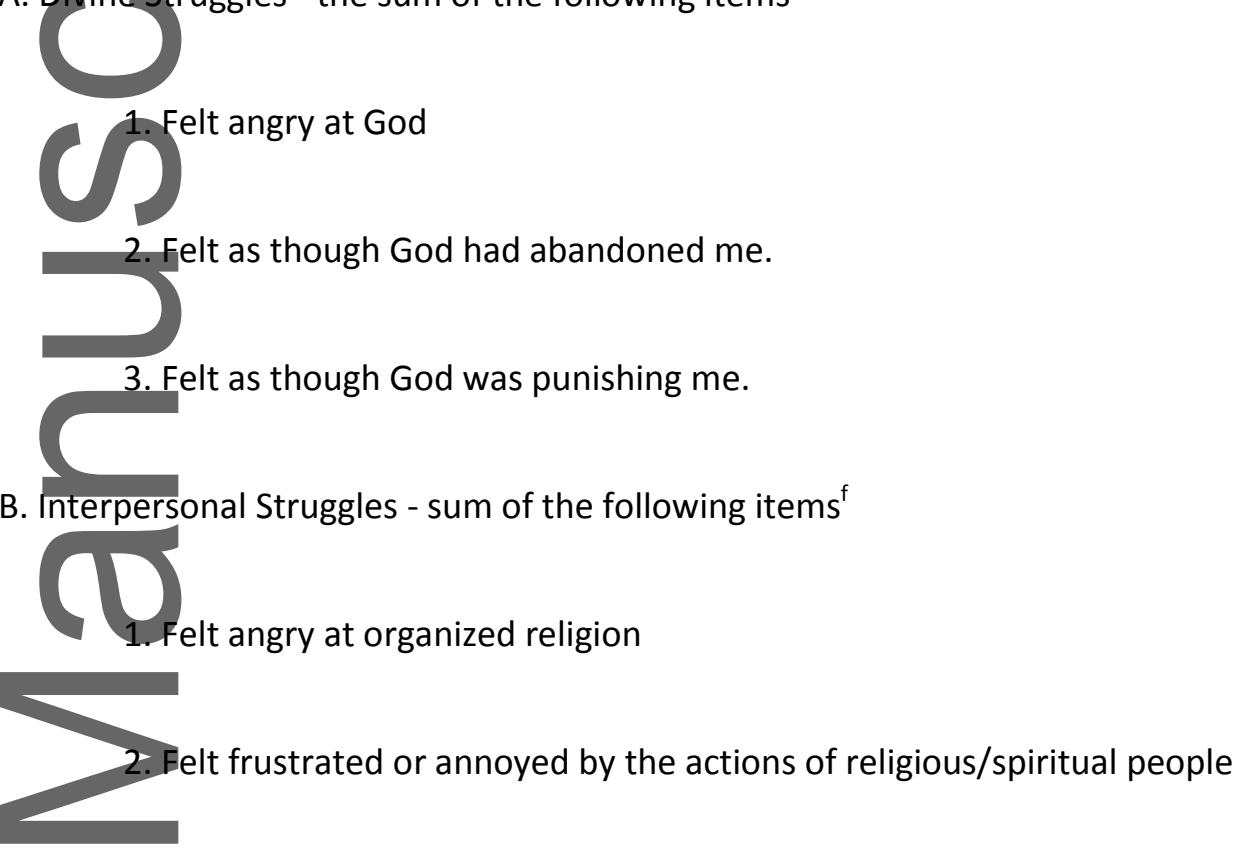

3. Was concerned that other people did not respect my religious/spiritual beliefs

C. Demonic Struggles - sum of the following items ${ }^{f}$

1. Worried that the problems I was facing were the work of the devil or evil spirits.

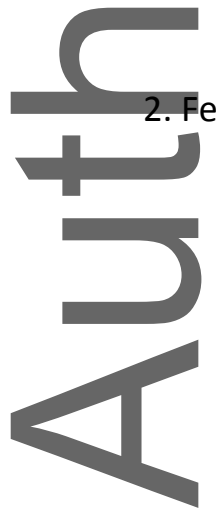

This article is protected by copyright. All rights reserved. 
3. Felt as though the devil (or an evil spirit) was trying to turn me away from what is good.

D. Intrapersonal Struggles - sum of the following items ${ }^{f}$

1. Worried that my actions were morally or spiritually wrong.

2. Felt torn between what I wanted and what I knew was morally (or spiritually) right.

3. Felt guilty for not living up to my (highest) moral standards.

E. Crisis of Ultimate Meaning - sum of the following items ${ }^{f}$

1. Questioned whether my life will really make any difference in the world.

2. Felt as though my life had no deep meanig.

3. Had concerns about whether there is any ultimate purpose to life or existence.

${ }^{a}$ These items were scored in the following manner (coding in parenthesis): no, symptom is not present (0); yes, symptom is present (1).

${ }^{\mathrm{b}}$ This item was scored in the following manner: only a little (1); some difficulty (2); a great deal (3).

${ }^{c}$ This item was scored in the following manner: money let over (1); just enough (2), not enough to make ends meet (3).

${ }^{d}$ These items were scored in the following manner: excellent (1); good (2); fair (3); poor (4). 
${ }^{\mathrm{e}}$ These items were scored in the following manner: strongly disagree (1); disagree (2); uncertain (3); agree (4); strongly agree (5).<smiles>C1CCC(C2CCCCC2)CC1</smiles>

${ }^{f}$ These itemswere scored in the following manner: not at all (1); a little bit (2); somewhat (3); quite a bit (4); a great deal (5).

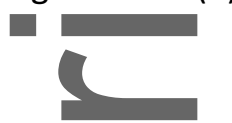

Table 2. Measurement error parameter estimates for multiple item study constructs

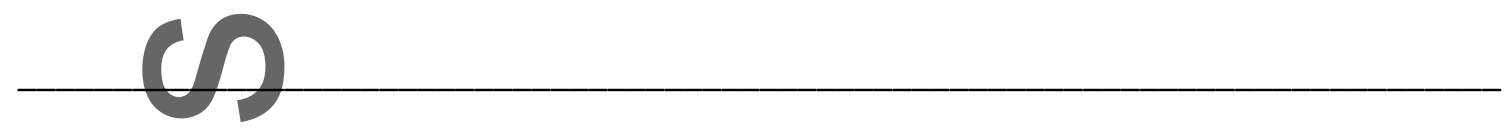

Construct
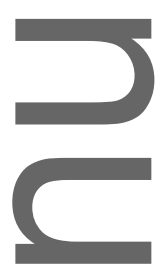

\section{Factor Loading ${ }^{\mathrm{a}} \quad$ Measurement}

1. Financial Strain

A. Difficulty paying bills ${ }^{c}$

.805

B. How finances work out

2. Neighborhood Conditions

A.

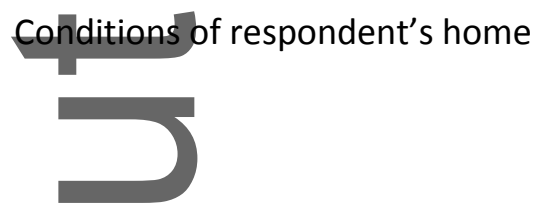

This article is protected by copyright. All rights reserved. 
B. Conditions of respondent's neighborhood

.873

.238

3. Anger

A. Most people lie

.675

.544

B. Friends are useful

.714

.490

C. Use unfair means

.798

.363

D. Dislike helping others

.674

.545

E. Others have hidden motives

.565

.681

4. Spiritual Struggles

A. Divine Struggles

.507

.743

B. Interpersonal Struggles

.532

.717

C. Demonic Struggles

.632

.601

D. Intrapersonal Struggles

.775

.400

$N=2,146$

${ }^{a}$ Factor loadings are from the completely standardized solution. The first-listed item for each latent construct was fixed at 1.0 in the unstandardized solution. 
${ }^{b}$ Measurement error terms are from the completely standardized solution. All factor loadings and measurement error terms are significant at the .001 level.

${ }^{c}$ Item content is paraphrased for the purpose of identification. See Table 1 for the complete text of each indicator.

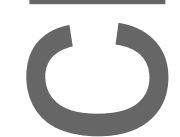

Table 3. Socioeconomic Status, Spiritual Struggles, and Health $(N=2,146)$
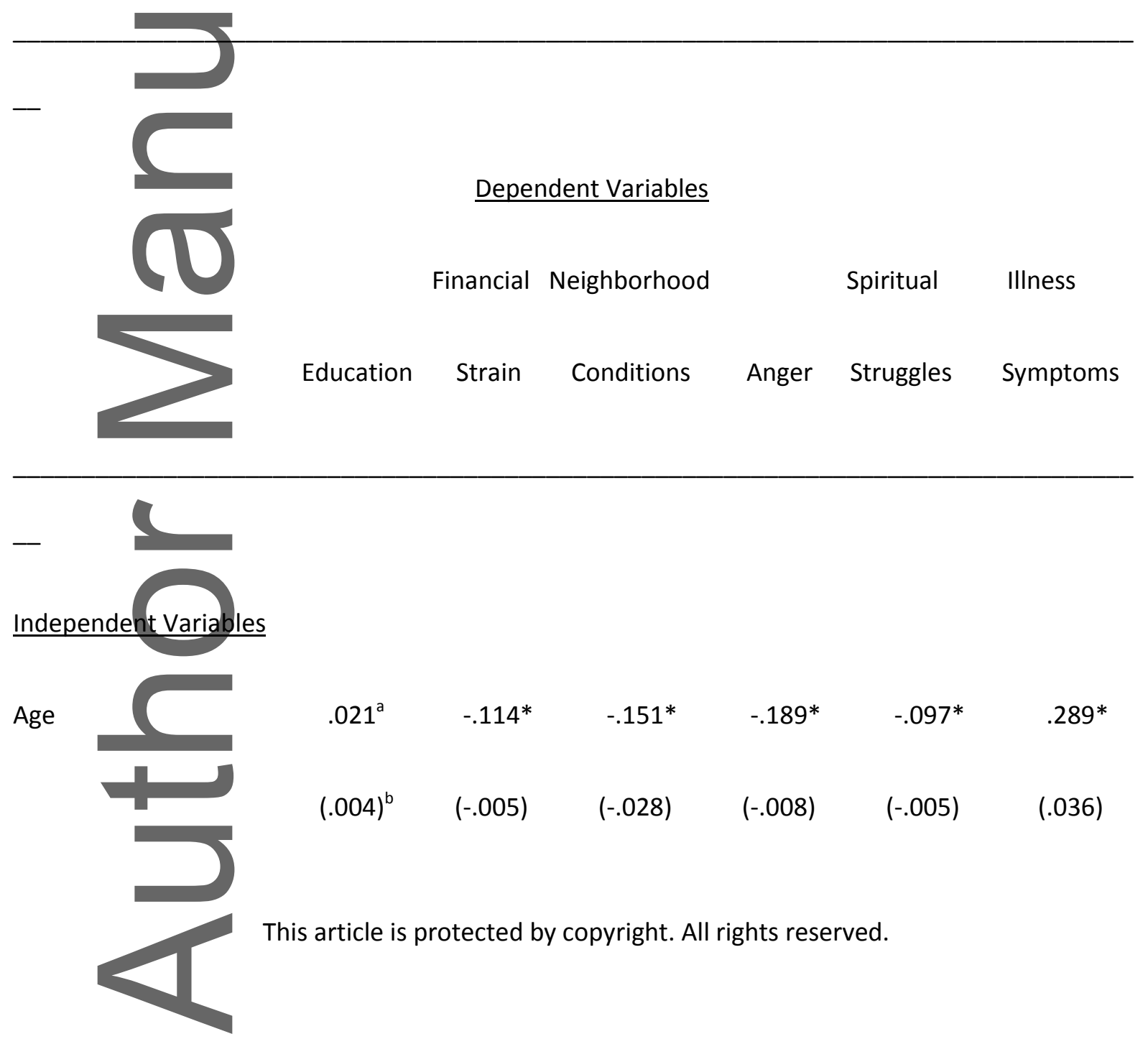
Sex

$\begin{array}{cccccc}.001 & -.056^{*} & .049 * & .143^{*} & .004 & -.117^{*} \\ (.009) & (-.097) & (.354) & (.222) & (.008) & (-.558) \\ -.116^{*} & .104^{*} & .125^{*} & .128^{*} & .055^{*} & -.012 \\ (-1.007) & (.248) & (1.124) & (.271) & (.145) & (-.075)\end{array}$

Education

$\begin{array}{ccccc}-.292 * & -.228 * & -.250 * & -.007 & -.068 * \\ (-.080) & (-.257) & (-.061) & (-.002) & (-.051)\end{array}$

Financial Strain

\begin{tabular}{|c|c|c|c|}
\hline $.269 *$ & $.111^{*}$ & $.256^{*}$ & $.192^{*}$ \\
\hline 1.106) & (.099) & $(.285)$ & $(.527)$ \\
\hline & $.109 *$ & .026 & $.099 *$ \\
\hline & \multirow[t]{3}{*}{$(.024)$} & $(.007)$ & $(.066)$ \\
\hline & & $.217^{*}$ & $.055^{*}$ \\
\hline & & $(.271)$ & \\
\hline
\end{tabular}

Neighborhood

Conditions

Anger

Spiritual Struggles

$.171^{*}$

(.422)

Multiple $\mathrm{R}^{2}$

.014

.124

.236

.246

.197

.204 
${ }^{a}$ Standardized regression coefficient

${ }^{b}$ Metric (unstandardized) coefficient
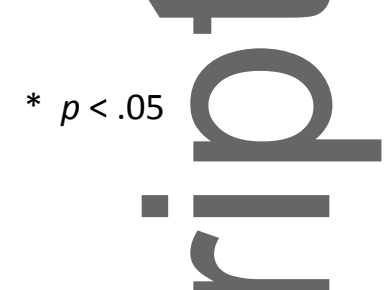

U

ஸ

$\longrightarrow$

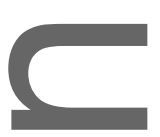

o
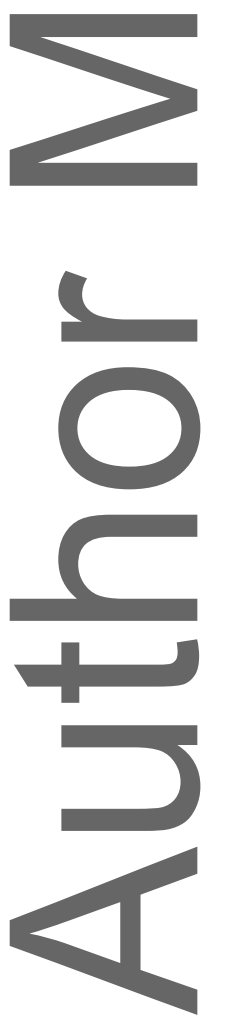

This article is protected by copyright. All rights reserved. 